\title{
Referral trends in mental health services for adults with intellectual disability and autism spectrum disorders
}

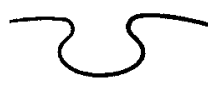

\author{
E L I A S T S A K A N I KO S King's College London, UK \\ P E T E R S T U R M E Y City University of New York, USA \\ H E L E N C O S T E L L O King's College London, UK \\ G E R A L D I N E H O L T King's College London, UK
}

N I C K B O U R A S King's College London, UK

ABSTRACT Researchers have paid increasing attention to mental health issues in adults with autism spectrum disorders (ASDs) over the last decades. However, little is known about how rates of clinical referrals, types of mental health diagnoses and treatment in adults with ASDs and intellectual disability have changed. We examined patterns of change in referral trends to specialist mental health services in south London from 1983 to $2000(\mathrm{~N}=137)$. The majority of the cases $(58.4 \%)$ did not have a diagnosable psychiatric disorder. Schizophrenia was the most frequent psychiatric diagnosis followed by depression, adjustment reaction and anxiety. There was a significant change in the rate of referrals, an increase in the diagnosable psychiatric disorders over time and a significant reduction of medication at time of referral. There were no significant changes in the use of other therapeutic interventions. The proportion of participants living independently increased. Implications for services and future research are discussed.

ADDRESS Correspondence should be addressed to: PROFESSOR NICK BOURAS, King’s College London, Institute of Psychiatry, MHIiLD-York Clinic Guy's Hospital, 47 Weston Street, London SE1 3RR, UK. e-mail: nick.bouras@kcl.ac.uk
KEYWORDS adult autism; dual diagnosis; intellectual disability; mental health services; mental retardation

People with intellectual disability (ID) and autism spectrum disorders (ASDs) have been shown to be more prone to mental health problems than people with intellectual disability alone (Bradley et al., 2004; Morgan et al., 2003), although not all studies have reported this (Tsakanikos et al., in press). Psychiatric disorders, especially anxiety and depression, are 
A U TIS M $11(1)$

common in people with ASDs (Gillberg, 1999; Gillberg and Billstedt, 2000; Howlin, 2000).

The clinical evaluation of people with ASDs and intellectual disability remains a diagnostic challenge (see Deb et al., 2001). On the one hand, people with intellectual disability may have autistic-like traits, although these may not be sufficient to warrant a diagnosis of autism. On the other hand, it is not easy to assess the extent to which the pathological factors that cause autism may contribute to, or even be responsible for, the existing intellectual disability (Berney, 2000; O’Brien and Pearson, 2004). Diagnostic obstacles increase when assessing mental health in people with autism and intellectual disability, mainly due to the communication difficulties often inherent in autism (Howlin, 1997; Noens and van Berckelaer-Onnes, 2004; Rapin and Dunn, 2003).

In the past, clinicians were less inclined to label people with intellectual disability with another clinical diagnosis, even if they displayed overt symptoms of psychopathology (Borthwick-Duffy, 1994; Reiss and Szyszko, 1983). In recent years, there has been a widespread perception that ASDs have increased (Charman and Clare, 2004; Medical Research Council, 2001; Roberts, 2004). For example, the California Health and Human Services Agency (1999) examined the rates of people with autism entering the local services system from 1987 to 1998. The report concluded that there had been a rise in the administrative prevalence of autism spectrum disorders over time in California.

Fombonne (2003) reported that the prevalence of ASDs in the literature was much lower in the 1960s and 1970s and has increased dramatically since that time. One possible explanation is that increased professional awareness, followed by changes in diagnostic practice, earlier detection, the broadening of diagnostic criteria, and the availability of services specific to autism, have combined to make the identification of people with autism more likely (Fombonne, 2003; Medical Research Council, 2000; Wing and Potter, 2002). Greater awareness of ASDs might also impact clinical practice with adults with developmental disabilities. Therefore, the aims of the present study were to examine the pattern of mental health diagnoses and the referral trends over the last two decades for adults with ASDs and intellectual disability to specialist mental health services.

\section{Method}

\section{Design}

This was a descriptive analysis of clinical referrals between 1983 and 2000 to specialist mental heath services in south-east London. In order to examine trends over time, referrals were grouped into three time bands 
TSAKANIKOS ET AL.: MENTAL HEALTH AND AUTISM (1983-8, 1989-94 and 1995-2000) reflecting the closure of two local long-stay institutions in 1988 and 1994 (Bouras et al., 2003).

\section{Participants}

Eligibility criteria for the study were: mental retardation (F70-73) (ICD-10 diagnostic criteria: World Health Organization, 1992), significant social impairment, and a diagnosis of ASD (F84) according to ICD-10 criteria. The degree of ID was coded on ICD criteria into mild (F70), moderate (F71) or severe (F72-73). Psychiatric diagnoses were made by a psychiatrist following clinical interviews with key informants and patients as part of delivering a clinical service. Two psychiatrists further agreed on the diagnosis by using the clinical criteria of ICD-10. The final sample size $(\mathrm{N}=$ 137) represented 15.0 percent of the total number of referrals during these 18 years. These were all new referrals (i.e. 137 distinct individuals rather than individuals who were seen in all three time bands and were being rereferred).

\section{Data recording}

The data were recorded at initial assessment using the Assessment and Information Rating Profile (Bouras and Drummond, 1989). The 12 variables that were recorded were: age, ethnicity (white, Afro-Caribbean, Asian, and other non-white), gender, source of referral, type of residence, psychiatric diagnosis, epilepsy, degree of intellectual disability, further therapeutic intervention, type of medication (psychotropics, sedatives, anti-convulsants, combinations, PRN medication or none), admission to inpatient mental health unit, and year of referral. Psychiatric diagnosis was grouped in the following major ICD-10 categories: no diagnosable disorder, schizophrenia spectrum (F20-27), personality disorder (F60-69), anxiety (F40-48), depressive disorder (F32-39), adjustment reaction (F43), dementia (F00-03) or other. The category 'other' included a small number of cases diagnosed as delirium (F05), eating disorders (F50), and hyperkinetic disorders (F90).

\section{Data analysis}

Simple univariate analyses were used to describe the frequencies of psychiatric diagnoses. Changes over time were analysed by $\chi^{2}$-tests to examine whether there were any statistically significant changes over time. In order to avoid a substantial number of comparisons (and therefore type I errors) we selectively tested the statistical significance of changes that were both consistent and meaningful: the increase in the psychiatric diagnoses and the decreased use of prescribed medication, supported housing and hospital admission. 
A U TIS M $11(1)$

\section{Results}

Table 1 presents changes in the proportion of patients over time by gender, age and ethnicity.

The proportion of patients by source of referral, type of residence, and degree of intellectual disability is shown in Table 2. The source of referral

Table I Patients by gender, mean age and ethnicity over time

\begin{tabular}{|c|c|c|c|c|c|c|c|c|}
\hline & \multicolumn{2}{|c|}{ 1983-8 } & \multicolumn{2}{|c|}{ 1989-94 } & \multicolumn{2}{|c|}{$1995-2000$} & \multicolumn{2}{|c|}{ All years } \\
\hline & no. & (\%) & no. & (\%) & no. & (\%) & no. & (\%) \\
\hline Total & 55 & & 31 & & 51 & & 137 & \\
\hline \multicolumn{9}{|l|}{ Gender: } \\
\hline Male & 37 & $(67.3)$ & 21 & $(67.7)$ & 41 & $(67.7)$ & 92 & $(67.2)$ \\
\hline Female & 18 & (32.7) & 10 & (32.3) & 20 & (33.3) & 45 & (32.8) \\
\hline Age [mean] & [28.5] & & {$[26.8]$} & & [29.2] & & {$[28.4$} & \\
\hline \multicolumn{9}{|l|}{ Ethnicity: } \\
\hline White & 45 & $(81.8)$ & 16 & $(51.6)$ & 37 & $(72.5)$ & 98 & (7I.5) \\
\hline Afro-Caribbean & 9 & $(16.4)$ & 11 & $(35.5)$ & II & $(21.6)$ & 31 & (22.6) \\
\hline Asian & 1 & $(1.8)$ & 2 & $(6.4)$ & 1 & $(2.0)$ & 4 & $(2.9)$ \\
\hline Other non-white & 0 & $(0.0)$ & 2 & $(6.5)$ & 2 & (3.9) & 4 & (2.9) \\
\hline
\end{tabular}

Table 2 Patients by source of referral, residence and degree of intellectual disability over time

\begin{tabular}{|c|c|c|c|c|c|c|c|c|}
\hline & \multicolumn{2}{|c|}{ 1983-8 } & \multicolumn{2}{|c|}{ 1989-94 } & \multicolumn{2}{|c|}{$1995-2000$} & \multicolumn{2}{|c|}{ All years } \\
\hline & no. & (\%) & no. & (\%) & no. & (\%) & no. & (\%) \\
\hline \multicolumn{9}{|l|}{ Source of referral: } \\
\hline Primary care & 24 & $(43.6)$ & 20 & $(64.5)$ & 23 & $(45.1)$ & 67 & (47.5) \\
\hline Social services & 12 & $(21.8)$ & 2 & $(6.5)$ & 11 & $(21.6)$ & 25 & (19) \\
\hline Generic mental health & 19 & $(34.5)$ & 9 & $(29.0)$ & 17 & (33.3) & 45 & (32.8) \\
\hline \multicolumn{9}{|l|}{ Residence: } \\
\hline Family home & 26 & $(47.3)$ & 16 & $(51.6)$ & 28 & (54.9) & 70 & $(51.1)$ \\
\hline $\begin{array}{l}\text { Health service } \\
\text { residence }\end{array}$ & 10 & $(18.2)$ & 2 & $(6.5)$ & 0 & $(0.0)$ & 12 & $(8.8)$ \\
\hline Independent & 0 & $(0.0)$ & 1 & $(3.2)$ & 4 & $(7.8)$ & 5 & $(3.6)$ \\
\hline Supported housing & 19 & $(34.5)$ & 12 & $(38.7)$ & 19 & $(37.3)$ & 50 & (36.5) \\
\hline $\begin{array}{l}\text { Degree of intellectual } \\
\text { disability: }\end{array}$ & & & & & I & & & \\
\hline Mild (F70) & 18 & $(32.7)$ & 14 & $(45.2)$ & 25 & $(49.0)$ & 57 & $(41.6)$ \\
\hline Moderate (F7I) & 24 & $(43.6)$ & 9 & $(29)$ & 14 & (27.5) & 47 & (34.3) \\
\hline Severe (F72-73) & 13 & $(26.6)$ & 8 & $(25.8)$ & 12 & (23.5) & 33 & $(24.1)$ \\
\hline
\end{tabular}


TSAKANIKOS ET AL. : MENTAL HEALTH AND AUTISM

did not vary significantly over time $\left(\chi^{2}=5.25\right.$, d.f. $\left.=4, p>0.10\right)$. However, the proportion of patients by residence significantly varied across the three time bands $\left(\chi^{2}=15.21\right.$, d.f. $\left.=6, p<0.05\right)$, as there was a marked decrease in the proportion living in National Health Service residences $\left(\chi^{2}=11.21\right.$, d.f. $\left.=2, p<0.001\right)$ and a corresponding increase in the proportion living independently $\left(\chi^{2}=6.04\right.$, d.f. $\left.=2, p<0.05\right)$.

The proportion of patients by psychiatric diagnosis and epilepsy over time is presented in Table 3. The majority of the cases (58.4\%) did not have psychiatric disorder. Schizophrenia spectrum disorders were the most frequent psychiatric diagnosis (16.1\%) followed by depression (6.6\%), adjustment reaction $(5.1 \%)$, anxiety $(4.4 \%)$, personality disorder $(2.9 \%)$, dementia $(1.5 \%)$ and the 'other' category, including less frequent disorders $(5.1 \%)$. There was an overall statistically significant change in the proportion of the type of psychiatric diagnosis over time $\left(\chi^{2}=26.31\right.$, d.f. $=14, p<0.05)$. Specifically, there was a significant decrease in the proportion of cases with no diagnosable disorder $\left(\chi^{2}=10.95\right.$, d.f. $=2$, $p<0.01)$, and a significant increase in the 'other' category $\left(\chi^{2}=12.44\right.$, d.f. $=2, p<0.01)$. The differences in the other diagnostic categories were non-significant (all p $>0.20$ ).

The proportion of participants receiving further therapeutic intervention, admission to inpatient mental health units, and type of medication at

Table 3 Patients by type of psychiatric diagnosis and presence of epilepsy over time

\begin{tabular}{|c|c|c|c|c|c|c|c|c|}
\hline & \multicolumn{2}{|c|}{ 1983-8 } & \multicolumn{2}{|c|}{ 1989-94 } & \multicolumn{2}{|c|}{$1995-2000$} & \multicolumn{2}{|c|}{ All years } \\
\hline & no. & (\%) & no. & (\%) & no. & (\%) & no. & (\%) \\
\hline \multicolumn{9}{|l|}{ Psychiatric diagnosis: } \\
\hline No diagnosable disorder & 47 & $(74.5)$ & 17 & $(54.8)$ & 22 & $(43.1)$ & 80 & (58.4) \\
\hline $\begin{array}{l}\text { Schizophrenia spectrum } \\
\text { (F20-27) }\end{array}$ & 6 & $(10.9)$ & 6 & (19.4) & 10 & $(19.6)$ & 22 & $(16.1)$ \\
\hline $\begin{array}{l}\text { Personality disorder } \\
\quad(F 60-69)\end{array}$ & 2 & (3.6) & 2 & $(6.5)$ & 0 & $(0.0)$ & 4 & $(2.9)$ \\
\hline Anxiety (F40-48) & 1 & $(1.8)$ & 1 & (3.2) & 4 & (7.8) & 6 & $(4.4)$ \\
\hline $\begin{array}{l}\text { Depressive disorder } \\
\text { (F32-39) }\end{array}$ & 3 & (5.5) & 3 & (9.7) & 3 & $(5.9)$ & 9 & (6.6) \\
\hline Adjustment reaction (F43) & 1 & (I.8) & 2 & $(6.5)$ & 4 & $(7.8)$ & 7 & (5.I) \\
\hline Dementia (F00-03) & 1 & (1.8) & 0 & $(0.0)$ & I & $(2.0)$ & 2 & $(1.5)$ \\
\hline Other & 0 & $(0.0)$ & 0 & $(0.0)$ & 7 & $(13.7)$ & 7 & $(5.1)$ \\
\hline \multicolumn{9}{|l|}{ Epilepsy: } \\
\hline Absent & 41 & $(74.5)$ & 28 & $(90.3)$ & 45 & $(88.2)$ & 114 & (83.2) \\
\hline Generalized & 14 & $(25.5)$ & 3 & $(9.7)$ & 2 & (3.9) & 19 & (13.9) \\
\hline Localized & 0 & $(0.0)$ & 0 & $(0.0)$ & 4 & (7.8) & 4 & (2.9) \\
\hline
\end{tabular}


A U T IS M $11(1)$

time of referral over time is presented in Table 4 . In terms of medication at time of referral, there were significant differences over time $\left(\chi^{2}=30.85\right.$, d.f. $=10, p<0.001)$, mainly reflecting a significant increase in the patients receiving no medication $\left(X^{2}=14.84\right.$, d.f. $\left.=2, p<0.001\right)$, an overall decrease in the use of PRN (as required) medication $\left(\chi^{2}=13.31\right.$, d.f. $=$ $2, p<0.001)$, and a marginally insignificant decrease in the psychotropics $\left(\chi^{2}=5.31\right.$, d.f. $\left.=2, p=0.07\right)$. There was no statistically significant change across the three time bands in the proportion of cases that needed a further therapeutic intervention $\left(\chi^{2}<1\right)$, although there was a significant decrease in the proportion of cases that were admitted to an inpatient mental health unit $\left(\chi^{2}=8.43\right.$, d.f. $\left.=2, p<0.01\right)$.

\section{Discussion}

Most service users in this study were men in their late twenties, referred by their primary care physicians or generic mental health services, living with their families or in supported housing. Most had no psychiatric diagnosis, although approximately 15 percent had a diagnosis of a schizophrenia spectrum disorder and a further 15 percent had psychiatric diagnoses related to depression, anxiety and adjustment reaction. Approximately one-third of the sample took psychotropic medications and a further 6 percent took anticonvulsants. Only one-third of the cases were reported to be receiving other

Table 4 Patients by type of intervention, admission to a mental health unit and type of medication over time

\begin{tabular}{|c|c|c|c|c|c|c|c|c|}
\hline & \multicolumn{2}{|c|}{ 1983-8 } & \multicolumn{2}{|c|}{ 1989-94 } & \multicolumn{2}{|c|}{$1995-2000$} & \multicolumn{2}{|c|}{ All years } \\
\hline & no. & (\%) & no. & $(\%)$ & no. & $(\%)$ & no. & (\%) \\
\hline \multicolumn{9}{|l|}{$\begin{array}{l}\text { Further therapeutic } \\
\text { intervention: }\end{array}$} \\
\hline Present & 43 & $(78.2)$ & 23 & $(74.2)$ & 40 & $(78.4)$ & 106 & $(77.4)$ \\
\hline Absent & 12 & $(21.8)$ & 8 & $(25.8)$ & $\mathrm{II}$ & $(21.6)$ & 31 & (22.6) \\
\hline \multicolumn{9}{|c|}{ Admission to impatient unit: } \\
\hline Present & II & $(20)$ & 5 & $(16.1)$ & 1 & $(2.0)$ & 17 & $(12.4)$ \\
\hline Absent & 44 & $(80)$ & 26 & $(83.9)$ & 50 & $(90.0)$ & 120 & (87.6) \\
\hline \multicolumn{9}{|l|}{ Type of medication: } \\
\hline Psychotropics & 26 & $(47.3)$ & 9 & $(29.0)$ & 14 & $(27.5)$ & 49 & $(35.8)$ \\
\hline Sedatives & 5 & $(9.1)$ & 0 & $(0.0)$ & 3 & $(5.9)$ & 8 & $(5.8)$ \\
\hline Anti-convulsants & 5 & (9.1) & 2 & $(6.5)$ & 2 & (3.9) & 9 & (6.6) \\
\hline PRN only & 1 & (1.8) & 6 & (19.4) & I & $(2.0)$ & 8 & (5.8) \\
\hline Combinations & 10 & (18.2) & 5 & $(16.1)$ & 6 & (II.8) & 21 & (I5.3) \\
\hline None & 8 & (I4.5) & 9 & $(29.0)$ & 25 & $(49.0)$ & 42 & (30.7) \\
\hline
\end{tabular}


services for their mental health needs. There were some significant trends over time, including an increase in the number of participants with a psychiatric diagnosis and a decreased used of prescribed medication.

These findings have a number of implications for mental health services for adults with ASDs and intellectual disabilities. First, mental health problems do occur in this group. Issues such as the differential diagnosis and treatment of psychoses in people with autism and intellectual disability have received some attention in previous research (Deb et al., 2001). The reliability of the differential diagnosis of these conditions in people with ASDs has received scant attention. The possibility of confusing symptoms of ASDs (e.g. firmly held strange beliefs relating to obsessions and special interests) with delusions requires further attention. Likewise the differentiation between the decline in social functioning seen in psychotic disorders and the withdrawal and unusual social behaviours in ASDs requires further attention. The former represents a decline in existing functioning with a periodic course of episodes of psychosis and recovery in a person with a pre-existing disability, whereas the latter represents the pre-existing developmental disability, which is continuous and less variable. Hence a comprehensive history is essential in making such a differentiation.

Depression, anxiety and adjustment reactions are the most commonly presented disorders in outpatient psychiatric care. The observations made here indicate that there is much in common with outpatient psychiatric services in people with ASDs. However, people with ASDs may be more vulnerable to minor stressful life events, such as minor transitions and changes, than the general population, as these changes may interfere with rituals and obsessions associated with autism spectrum disorders. Management of this aspect of these disorders may be somewhat different than in the general population.

In this study 36.7 percent of the participants took psychotropic medications and a further 6.1 percent took anti-convulsant medications. These figures are broadly comparable to many other comtemporary reports of the prevalence of psychotropic medication in adults with developmental disabilities in community services (Bouras et al., 2003). However, only 23.1 percent were reported as receiving an adjunctive therapy, such as a behavioural intervention plan or other intervention. This is a surprisingly low figure and contrasts with reports of young children with autism spectrum disorders. For example, one study (Bibby et al., 2001) reported that 81 percent of 66 children with ASDs in early intervention services received special diets, mineral and vitamin supplements, secretin, infusions, homeopathic and sensory interventions. Perhaps this question was insensitive in detecting these. Future research should measure these other interventions more actively. 
In summary, a number of significant referral trends emerged after examining referrals of people with ASDs and intellectual disability, from 1983 to 2000, to specialized services in south-east London. These findings document the changing context in which psychiatric services are now provided. It is possible that enhanced accessibility to specialist mental health services for people with ASDs and intellectual disability has contributed to these trends, as similar trends have been identified in people with intellectual disability but without ASDs (Bouras et al., 2003). It is only recently that the role of specialist mental health services, in addition to access to generic mental health services, has been acknowledged (Department of Health, 2001).

\section{References}

Berney P. (2000) 'Autism: An Evolving Concept', British Journal of Psychology 176: $20-5$.

Bibby, P., eikeseth, S., MARTin, N.t., MUdford, O.C. \& Reeves, D. (2001)

'Progress and Outcomes for Children with Autism Receiving Parent-Managed

Intensive Interventions', Research in Developmental Disabilities 22: 425-47.

BORTHWICK-DUFFy, S. (1994) 'Epidemiology and Prevalence of Psychopathology in

People with Mental Retardation', Journal of Consulting and Clinical Psychology 62: 17-27.

BOURAS, N. \& DRUmmond, K. (1989) 'Community Psychiatric Services in Mental

Handicap', Health Trends 21: 72-8.

Bouras, N., COWley, A., holt, G., NeWton, J.t. \& sturmey, P. (2003)

'Referral Trends of People with Intellectual Disabilities and Psychiatric Disorders', Journal of Intellectual Disability Research 47: 439-46.

BRADley, E.A., SUMmers, J.A., WOOD, H.L. \& BRySOn, S.E. (2004) 'Comparing

Rates of Psychiatric and Behaviour Disorders in Adolescents with Young Adults with Severe Intellectual Disability with and without Autism', Journal of Autism \& Developmental Disorders 34: 151-61.

California health and human services agency (1999) Changes in the Population of Persons with Autism and Pervasive Developmental Disorders in California's Developmental Services System: 1987 through 1998. Department of Developmental Services, California Health and Human Services Agency, Sacramento, CA.

Charman, T. \& Clare, P. (2004) Mapping Autism Research: Identifying UK Priorities for the Future. London: National Autistic Society.

Deb, S., Matthews, T., holt, G. \& Bouras n. (2001) Practice Guidelines for the Assessment and Diagnosis of Mental Health Problems in Adults with Intellectual Disability. Brighton: Pavilion.

Department of Health (2001) Valuing People: A New Strategy for Learning Disability for the 21st Century. London: HMSO.

fombonne, E. (2003) 'Epidemiological Surveys of Autism and Other Pervasive Developmental Disorders: An Update', Journal of Autism and Developmental Disorders 33: 365-82.

Gillberg, c. (1999) 'Autism and Its Spectrum Disorders', in N. BOURAs (ed.), Psychiatric and Behavioural Disorders in Developmental Disabilities and Mental Retardation, pp. 73-95. New York: Cambridge University Press. 
Gillberg, C. \& Billstedt, E. (2000) 'Autism and Asperger Syndrome:

Co-existence with Other Clinical Disorders', Acta Psychiatrica Scandinavica 102:

321-30.

Howlin, P. (1997) Autism: Preparation for Adulthood. London: Routledge.

Howlin, P. (2000) 'Outcome in Adult Life for More Able Individuals with Autism or Asperger Syndrome', Autism 4 (1): 63-83.

Medical ReSEARCh COUnCil (2001) Review of Autism Research: Epidemiology and Causes. UK: Medical Research Council.

Morgan, C.N., ROY, M. \& CHANCE, P. (2003) 'Psychiatric Comorbidity and Medication Use in Autism: A Community Survey’, Psychiatric Bulletin 27: 378-81. noens, i. \& Van Berckelaer-onnes, i. (2004) 'Making Sense in a Fragmentary World: Communication in People with Autism and Learning Disability', Autism 8 (2): 197-218.

o'brien, G. \& Pearson, J. (2004) 'Autism and Learning Disability', Autism 8 (2): $125-40$.

RAPIN, I. \& DUNN, M. (2003) 'Update on the Language Disorders of Individuals on the Autistic Spectrum’, Brain and Development 25: 166-72.

ReISS, S. \& SZYSZKO, R. (1983) 'Diagnostic Overshadowing and Professional Experience in Mentally Retarded Persons', American Journal of Mental Deficiency 87: 396-402.

roberts, J.M. (2004) A Review of the Research to Identify the Most Effective Models of Best Practice in the Management of Children with Autism Spectrum Disorders. Sydney: Centre for Developmental Disability Studies.

tSakanikos, e., Costello, h., holt, G., Bouras, N., Sturmey, P. \& NEWTON, T. (in press) 'Psychopathology in Adults with Autism and Intellectual Disability', Journal of Autism and Developmental Disorders.

Wing, L. \& POtTER, D. (2002) 'The Epidemiology of Autistic Spectrum Disorders: Is the Prevalence Rising?', Mental Retardation and Developmental Disabilities Research Reviews 8: 151-61.

WORld Health organization (1992) The ICD-10 Classification of Mental and Behavioural Disorders: Clinical Descriptions and Diagnostic Guidelines. Geneva: WHO. 